\title{
Fantasmas na máquina: Estrutura e movimento nos filmes de Ernie Gehr
}

Lucas Baptista

Resumo: Este artigo propõe uma interpretação de alguns filmes do cineasta norte-americano Ernie Gehr, argumentando que eles respondem aos anseios de duas tendências de composição: por um lado, uma busca por estruturas simples, com número reduzido de elementos e baseadas em procedimentos repetitivos; por outro lado, um interesse pelo que há de mais efêmero na experiência cinematográfica, a inevitável passagem dos materiais no decorrer da projeção.

Palavras-chave: Ernie Gehr; composição; cinema estrutural; movimento.

Abstract: Ghosts in the machine: structure and movement in Ernie Gehr's films - This paper proposes an interpretation of six films of the American filmmaker Ernie Gehr. It argues that these films are a response to the yearnings of two trends of composition: on one hand, a search for simple structures with a reduced number of elements and based on repetitive proceedings; on the other hand, an interest on the ephemeral side of cinematic experience, the inevitable flowing of materials during the projection.

Keywords: Ernie Gehr; composition; structural film; movement.

Cristal e chama, duas formas da beleza perfeita da qual o olhar não consegue desprender-se, duas maneiras de crescer no tempo, de despender a matéria circunstante, dois símbolos morais, dois absolutos, duas categorias para classificar fatos, ideias, estilos e sentimentos. - Italo Calvino (1990, p. 95)

O que permanece após o encontro com um filme? Ou ainda, no espírito da citação de Calvino: que imagem um filme cria no espectador, após este encontro?

A natureza da experiência cinematográfica é transitória. Cada átomo de informação apresentado é imediatamente levado pelo projetor, e qualquer constelação de sentido que 
se destaque é colocada sob a perspectiva da incontornável sucessividade. Se em artes como a pintura, a escultura ou a arquitetura é possível ao espectador se referir a partes estáticas, é porque tais obras se desdobram espacialmente de maneira estável, fazendo com que o tempo da experiência, se variado, o seja por fatores externos. O espectador da escultura pode mover-se à sua volta, tocá-la, observar repetidas vezes suas proporções: tudo colabora para que a imagem mental da obra seja lentamente estabelecida no decorrer deste processo. No cinema é a convenção em si e a constituição material das obras que tornam esta tarefa impossível. Encarar uma obra cinematográfica é colocar-se à disposição de um encadeamento visual e sonoro, marcado por um ritmo específico, ordenado e calibrado de antemão. No encontro com um filme, não há objeto estável; imagens e sons, após a acelerada impressão sensorial, desaparecem. Como a música, o cinema é uma arte que nasce e morre no tempo.

Numa investigação sistemática, não poderíamos ignorar a base cognitiva e a contribuiçãa do espectador à experiência. O que nos interessa, entretanto, é um terceiro elemento: a composição da obra. De que maneira a constituição de um filme afeta este processo, ou sugere as margens pelas quais ele ocorre? De que maneira os princípios de criação e organização dos filmes se refletem na imagem que criam no espectador?

Certas obras, pela força de suas ilusões ou pela coerência de suas trajetórias, se estendem com amplitude no teatro da memória. Neste caso, uma forma se revela com alguma clareza: a disposição das partes tem o propósito de um discurso, pois o que nos é dado é a necessidade desta ordem, sua estrutura direcionada. Recorremos mentalmente a essas obras como recorremos a poemas cuja métrica delimita e cujas rimas antecipam as palavras. Como um exemplo desta tendência poderíamos citar "Um corpo que cai" (Vertigo, Alfred Hitchcock, 1958), um filme em que as simetrias, inversões e recorrências de motivos fazem mais do que facilitar a fixação do arco dramático: elas são a própria definição deste arco, como um traçado feito pelo autor, seguindo as estritas leis da causalidade narrativa.

De outras obras somos capazes de reter apenas um instante particular, um gesto, um corte, um fragmento no qual podemos reconhecer um tema, uma emoção, um temperamento familiar. Em tais obras o domínio exercido não é o da estrutura, mas o da atmosfera ou da impressão. A geometria se dissolve conforme avançamos, e ao final do percurso, mais do que uma ordem, sentimos que certas coisas desapareceram perante nossos olhos, e que a projeção nos permitiu vislumbrar, em sua impassível regularidade, algo da ordem do inefável. Mas a reverberação posterior não rara nos parece mais que um resquício da experiência: parece a experiência mesma, sintetizada e simbolizada em uma de suas partes, vaga e indefinida como esta seja. Um filme como "Dog Star Man" (Stan Brakhage, 1962-64) é emblemático nesse sentido, com imagens e movimentos sendo variados em um número tão elevado de combinações que apenas alguns pontos se destacam, como se nos restassem apenas os centros gravitacionais ao redor dos quais testemunhamos o vórtice incessante. Se Hitchcock pode ser considerado um modelo de 
cineasta da ordem geométrica e direcionada, Brakhage seria sua antítese, a quintessência da impressão fugidia e resistente à disposição cristalina.

Essas duas direções, mais do que categorias, nos servem como tendências ou referências. É provável que qualquer filme deva necessariamente se erigir sobre os pilares do traçado consciente e da abertura à efemeridade. Não nos cabe aqui esgotar a questão, portanto, mas utilizá-la como ponto de partida.

É um lugar comum que o cinema narrativo, de maneira geral, opera por um princípio semelhante ao que descrevemos no filme de Hitchcock - do que decorre sua dependência de elementos como o plano e o raccord, fundamentais na criação de uma estabilidade a ser conduzida sob a pressão da causalidade. Da mesma forma, é sabido que grande parte do cinema experimental se pauta por outras questões, muitas vezes rejeitando a lógica dramática, a caracterização e mesmo as noções básicas de plano ou decupagem. O que será proposto a seguir é um cruzamento dessas duas vertentes, na tentativa de observar um conjunto de obras que possui interesse evidente na elaboração estrutural, mas também no caráter passageiro e puramente material da experiência fílmica. Isto será realizado através dos filmes de Ernie Gehr, e veremos como suas estratégias envolvem os diferentes aspectos do movimento cinematográfico.

Há uma história frequentemente citada sobre a entrada de Gehr no mundo do cinema, e que parece revelar, senão o caráter de seus filmes, ao menos algo das intenções e dos interesses que os sustentam. Recém-dispensado do exército, Gehr teria vagado pela noite nova-iorquina sob forte chuva até se abrigar num prédio, que logo descobriu ser um cinema onde ocorria a exibição de alguns filmes de Stan Brakhage. Segundo o relato, esta sessão teve um efeito tão intenso sobre Gehr que, nas semanas seguintes, ele decidiu fazer seus próprios filmes. Ao ser perguntado sobre o que o atraiu nos filmes de Brakhage, ele respondeu: "seu grau de abstração, sua preocupação com textura, cor e ritmo, em vez de trama, suspense e drama psicológico". Não tendo qualquer formação cinéfila ou conhecimento prático sobre cinema, Gehr frequentou o Millennium Film Workshop, administrado por Ken Jacobs, onde aprendeu a utilizar as ferramentas necessárias. Quando uma câmera não estava disponível, tomava em mãos apenas um fotômetro e vagava pela cidade medindo a luminosidade em diferentes locais e ocasiões, se acostumando com o novo instrumento, tornando-se, ele próprio, sensível à luz (MacDONALD, 2006, p. 361-363).

Uma atenção às condições materiais do cinema, da filmagem até a exibição, se coloca desde o início como uma de suas marcas, rendendo uma aproximação com a tendência chamada à época de "cinema estrutural". O termo, estabelecido por P. Adams Sitney (2002, p. 347-370), abarca certos filmes surgidos em meados dos anos 1960 nos quais as preocupações modernistas da vanguarda americana pareciam elevadas a um grau máximo. Se a abstração, a textura, a cor, o ritmo e a rejeição da narrativa eram tópicos recorrentes em filmes anteriores ao período, na obra de Michael Snow, Hollis Frampton, Joyce Wieland e Paul Sharits isto se daria através de uma concentração extrema, em uma estrutura decorrente de procedimentos repetitivos, que estabelece um "formato" geral e que se coloca como a primeira impressão na mente do espectador. Há aqui uma tentativa 
de dar à obra um tipo de traçado reconhecível, e que poderia delinear o material fílmico na experiência temporal da mesma maneira que um objeto tem seu perfil delineado no espaço. No centro da definição do cinema estrutural está uma tensão entre a organização diagramática da forma e o fluxo temporal inerente à projeção.

\section{Morning (1968) ${ }^{1}$}

"Morning" é a primeira obra "oficial" de Gehr. O filme se inicia com planos de uma janela, vista por dentro de um quarto. A passagem de um plano a outro é enfatizada tanto pela aceleração da montagem como pelas variações de luz, perceptíveis por seu contraste elevado. Após alguns segundos de escuridão, outros planos da mesma janela, agora a uma distância maior, possibilitando a visão do quarto. O enquadramento centraliza a janela; no lado esquerdo vemos uma cama, e no lado direito uma estante. Esta é a arena do filme, onde ocorre a principal intervenção do cineasta: uma série de alterações na configuração da câmera, nas proporções do quadro e sobretudo na abertura do diafragma. Conforme o diafragma se fecha, a luz que entra pela janela é esmaecida, e percebemos com mais definição os contornos e detalhes dos objetos no quarto; mas em determinado ponto a luz se torna tão fraca que não é suficiente para iluminar o quarto - vemos, assim, apenas o contorno da janela, e dentro deste retângulo, o fundo em sua parca luminosidade. Conforme o diafragma se abre, os contornos se evidenciam; mas logo a luz se torna tão intensa que os objetos são envoltos em um halo dourado até finalmente mergulharem na luminosidade que toma conta de todo o espaço, tornando invisível mesmo o contorno da janela. As variações são por vezes graduais, como num crescendo em direção à claridade ou escuridão, e por vezes intermitentes, com saltos e intervalos maiores.

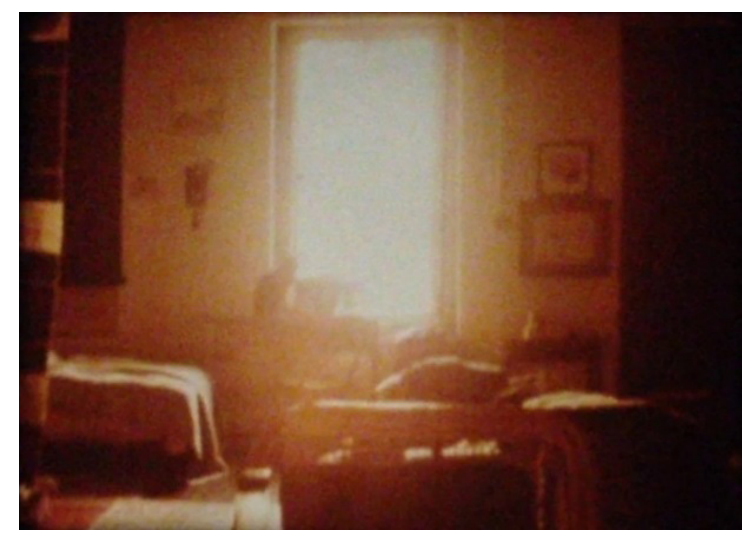

1 Cada imagem no corpo do texto foi retirada do filme da seção correspondente. Daí não haver legenda específica. 
A concentração estrutural do filme é evidente. Tendo fixado a direção da câmera e os eventos perante ela, Gehr se dedica à manipulação de poucos parâmetros. Toda a modulação presente em sua duração se deve à variação luminosa, com breves intervalos em que o quadro é reduzido ou ampliado. "Morning" investiga diretamente algo tomado como pressuposto por uma infinidade de filmes: a luz como aquilo que nos permite reconhecer objetos, espaços e eventos, por ser a própria substância do processo fotográfico. Sendo a luz um dos fatores primordiais, é perfeitamente possível que toda a composição seja organizada em torno dela: em princípio, não é necessário que nada além da luz seja alterado em um filme. Existe afinal uma escala luminosa; existem pontos onde a luz impede o reconhecimento da realidade espacial, seja este o domínio da clareza ou da escuridão. A liberdade do cineasta nessa escala é análoga à de um músico que improvisa com valores dinâmicos, atingindo ora o silêncio, ora o limite superior da audição. A cada operação, o que resulta é um movimento - mas um movimento possível apenas no cinema, por depender da luz projetada no tempo. O movimento aparenta ser contínuo quando o pulso da luz surge e desaparece do quarto como uma única onda de energia - o que é reforçado pelo único movimento "de fato" no interior do quadro: um gato que atravessa o espaço. Mas quando o movimento é fragmentado, quando ocorrem saltos entre as configurações, percebemos o fator rítmico que ao mesmo tempo isola cada fotograma e os submete ao padrão articulado. A relação entre "fotograma" e "plano" é assim redefinida nos termos próprios do filme; um plano é nada mais que uma região do espectro da luz estendida pelo tempo:

Um fotograma tem a ver com uma intensidade particular de luz, uma imagem, uma composição congelada no tempo e no espaço. Um plano tem a ver com a intensidade variável da luz, um balanço interno de tempo dependente do movimento intermitente e um movimento dentro de um determinado espaço dependente da persistência da visão. (GEHR, 1972, p. 36-37) ²

\section{Reverberation (1969)}

Em "Reverberation", Gehr parte de um material filmado nas ruas de Nova York, estendendo sua duração pela repetição dos fotogramas e alterando suas qualidades luminosas com uma impressora ótica. A imagem monocromática tem sua granulação intensificada, como se o próprio suporte borbulhasse constantemente. Durante todo o filme há um ruído extremamente denso, o som das perfurações da película, filtrado por algum tipo de eco ou compressor.

As imagens mostram um jovem casal na cidade. Eles estão com outras pessoas em um cruzamento, observando algo que se encontra fora de quadro; em seguida, são vistos

2 Todas as traduções são nossas. 
em outro espaço, uma calçada na frente de uma imensa parede de concreto. $\mathrm{O}$ fato de incluir pessoas, e mais especificamente, pessoas que parecem lidar com uma situação vagamente narrativa, faz com que o filme de Gehr tenha uma atmosfera insólita: a ocasião que envolve o casal nos é completamente alheia, apresentada de maneira elíptica, e não é sequer apresentada com nitidez, já que em vários momentos a imagem é tomada pela granulação brilhante. A constante manipulação termina por criar uma narrativa que envolve as pessoas enquadradas, mas as coloca em relação direta com os eventos puramente fílmicos, que ocorrem no suporte da representação. Quando o casal, de costas para a câmera, observa algo que parece ocorrer em uma região distante da rua, a cena ganha um caráter escultural, típico de planos filmados em profundidade, mas isso coexiste com as mudanças de luminosidade efetuadas por Gehr, desde leves variações de brilho e contraste até um banho luminoso que dissolve todo o conteúdo em uma nuvem branca e metálica. Ouve-se ainda no decorrer de toda a cena o mesmo ruído assombroso, que dá um tom de perigo iminente à situação.

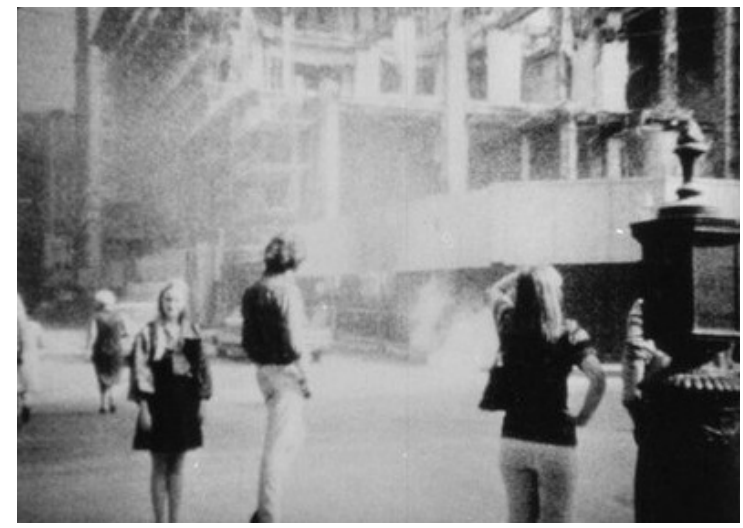

Em "Reverberation", a granulação e sua contraparte sonora são responsáveis pelo tom da narrativa, e pelo próprio fato de existir uma narrativa, ainda que vaga e incompleta, visto que não há relação sintática entre os planos apresentados. Todas as pessoas que habitam o filme o fazem como se estivessem imersas em um fluido denso e pesado. Os gestos são arrastados, o sentido é abstraído. Mesmo quando o homem e a mulher estão imóveis, eles parecem interagir com a grande câmara fílmica, que segue seu movimento particular, um campo de forças indiferentes à presença humana. O universo de "Reverberation" é um universo de grão e ruído, onde pessoas e eventos emergem como possibilidades, e onde sua própria existência é ressignificada pelas coordenadas da imagem e do som.

\section{Serene Velocity (1970)}

Um corredor universitário, vazio e à noite, é enquadrado simetricamente, com algumas luzes acesas dando ao espaço uma tonalidade azulada, quebrada apenas pelas 
sombras, as linhas brancas das lâmpadas fluorescentes e o vermelho das placas de saída. Gehr nos mostra este corredor seguindo um padrão de montagem: alguns fotogramas são apresentados de uma mesma posição; há então um corte para o mesmo enquadramento, o mesmo número de fotogramas, mas com um leve zoom in; em seguida, um corte para o mesmo enquadramento, o mesmo número de fotogramas, mas com um leve zoom out. A combinação dos zooms é como uma sístole e diástole em relação ao enquadramento inicial, o "ponto central" do filme.

Não há movimento no interior do espaço. Toda a progressão resulta da variação dos intervalos entre os fotogramas - as distâncias de um enquadramento a outro. O ritmo da variação é constante, mas as distâncias aumentam gradativamente, pois os enquadramentos se afastam cada vez mais do ponto central. Se em "Morning" a luz era o fator isolado e manipulado, em "Serene Velocity" isso ocorre com a distância focal da lente: é esta a "escala" escolhida por Gehr para realizar sua composição, desta vez com uma abordagem absolutamente regular.

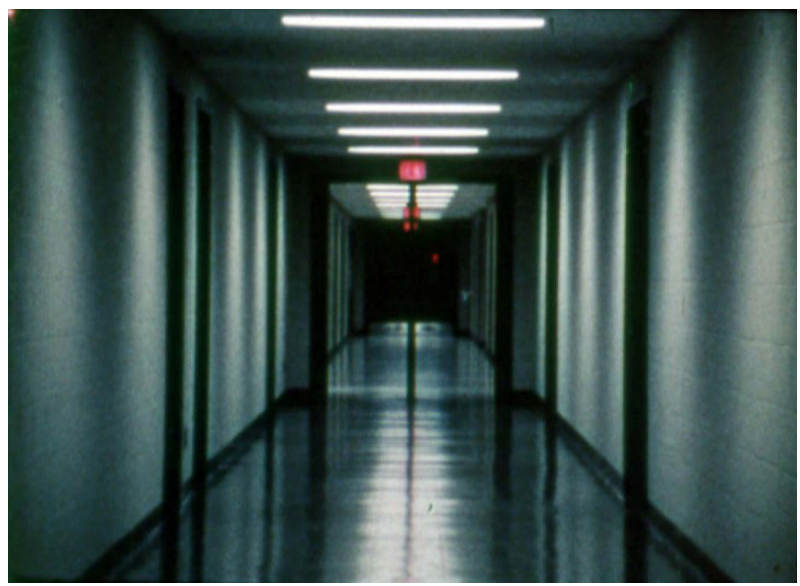

"Serene Velocity" se caracteriza também por um movimento propriamente fílmico e pela exploração de um "espectro", efetuada neste caso pela travessia do conjunto de possibilidades. É excluída apenas a região identificada com a continuidade, com o plano, o que decorre da escolha de um ponto central do qual os trechos posteriores irão se afastar. Não há mais a fluidez, apenas diferentes níveis de contraste. No início do filme, quando a distância entre os enquadramentos é pequena, as cores tremulam como se recémdesligadas de um movimento contínuo, e sua proximidade permite que o corredor seja percebido com certo volume e profundidade. A distância aumenta, contudo; o pulso se torna mais percussivo, e a profundidade do corredor dá lugar ao achatamento da tela, transformando os objetos e luzes em formas geométricas que, em sua alternância, sugerem um lento e prolongado efeito de flicker. 
"Serene Velocity" desenvolve um jogo perceptivo, uma investigação sobre a consistência de um "espaço-tempo fílmico", de um campo de fenômenos ópticos que só são possíveis devido ao aparato do cinema. Não experimentamos o corredor fora das coordenadas estipuladas, mas também não experimentamos as formas geométricas fora destas coordenadas. Devemos necessariamente integrar os dois pólos, também pelo ritmo imposto pela composição. O filme é como uma camada perceptiva através da qual podemos observar uma parte do mundo, mas uma camada que altera a própria substância da visão, que se revela um elemento ativo nesta cadeia.

\section{Still (1971)}

"Still" é dividido em cinco seções. Todas elas mostram uma rua filmada pelo mesmo ponto de vista. A primeira seção é silenciosa, mas da segunda em diante há som, que parece às vezes direto, e às vezes estreitamente relacionado à cena. Como em "Serene Velocity", uma única técnica é escolhida por Gehr: neste caso, uma série de sobreposições de imagens da mesma rua, sob o mesmo enquadramento, mas em diferentes momentos. Dessa forma, vê-se, por exemplo, um carro estacionado, e percebe-se que, por sua opacidade, ele é parte do plano "principal", enquanto ao mesmo tempo vê-se um segundo carro, translúcido, atravessar a tela, e compreende-se imediatamente que se trata de uma sobreposição. Gehr controla as sobreposições como diferentes tecidos que muitas vezes se somam ao plano principal. O cruzamento de suas características e níveis de transparência gera efeitos curiosos, como quando a sobreposição de um caminhão escuro atravessa a tela lentamente, ao mesmo tempo em que uma segunda sobreposição, mais transparente, de um táxi amarelo, atravessa a tela rapidamente - vê-se o táxi apenas enquanto ele passa pela área coberta pelo caminhão, pois o resto da tela é claro demais para que se possa perceber sua presença.

Cada uma das seções mostra a rua em uma época diferente do ano, o que é demonstrável tanto pela qualidade da luz como pelas folhas na árvore posicionada no lado esquerdo do quadro. Os dois extremos são a seção que ocorre no inverno, com a árvore seca e a luz mais difusa, e a seção que ocorre no verão, com a árvore já repleta de folhas e a luz claramente marcada. Há com isso uma influência direta sobre a vivacidade das cores, criando uma impressionante variedade cromática, com vermelhos, amarelos e verdes sendo esmaecidos ou dinamizados pela menor ou maior presença das sombras. Essa característica é expressa pelo elogio feito por Richard Foreman (1977, p. 28), de que seria "o primeiro filme de 'objetificação' de atmosfera, em que os objetos e as relações entre eles terminam por irradiar o clima que até então eu apenas conseguia pensar como 'conteúdo' em vez de 'contido'". 


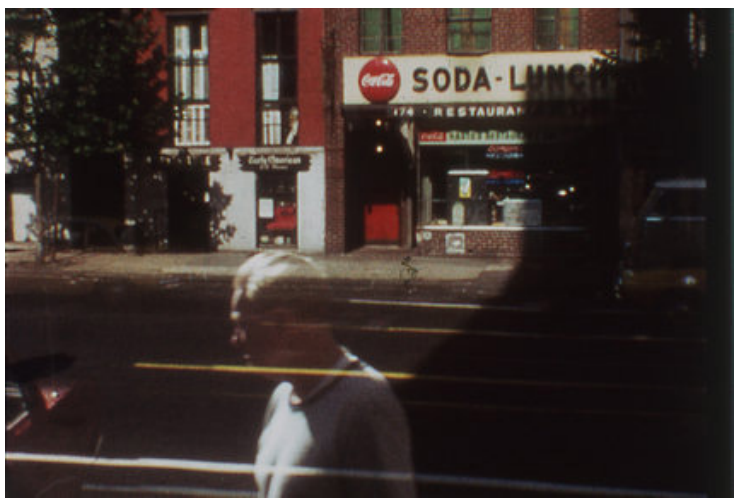

"Still" desenvolve uma "gramática da sobreposição". Se o filme ensina algo sobre as condições básicas do cinema, é que a percepção da solidez, ou ainda da opacidade dos objetos, se deve apenas à repetição de um padrão de luz sobre a mesma região do enquadramento. Assim como o movimento contínuo, a opacidade no cinema deve ser construída: ela existe apenas em condições específicas. A película em si é transparente. Quando nos deparamos com o vermelho da parede, isto significa que a composição daqueles fotogramas subtraiu verde e azul do feixe luminoso do projetor. Isso é tornado explícito no filme quando as diferentes camadas interagem, influenciando a constituição cromática dos objetos no decorrer de suas trajetórias. Se apenas a película transparente fosse exposta, veríamos a tela completamente branca. Um filme - qualquer filme - é uma composição de transparências e opacidades, de subtrações e combinações de formas e cores luminosas sobre a película para que o tempo da projeção seja modulado, esculpido com um sentido particular.

\section{Eureka (1974)}

"Eureka" se apropria de um único plano, um travelling frontal através da Market Street de São Francisco, filmado em 1906. O bonde sobre o qual a câmera se posiciona atravessa toda a extensão da rua, enquanto esta é cruzada por pedestres e outros veículos. O material original tem duração de aproximadamente cinco minutos, e corresponde a um exemplar dos registros urbanos, comuns no início do século XX, que utilizavam meios de transporte para posicionar a câmera, integrando-a ao espaço e ao movimento da cidade. O plano é retomado por Gehr, que repete cada fotograma de seis a oito vezes, estendendo a duração para cerca de 40 minutos enquanto altera os contrastes e flutuações de luz. A representação do movimento é reconfigurada pela extensão temporal, e os riscos na superfície da película são multiplicados e mais claramente percebidos. Veículos e pessoas, num registro histórico, coexistem com as marcas da própria história sobre o material fílmico. 


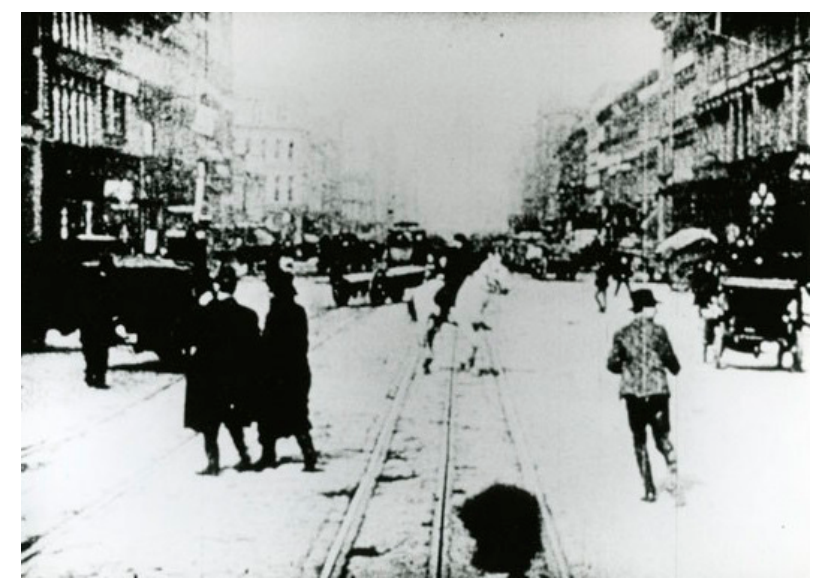

Mais uma vez, o movimento contínuo é reinterpretado por Gehr. Aqui, a continuidade é dilatada a partir de seus componentes elementares - os fotogramas -, criando uma linha discreta que mantém a estrutura inicial - o movimento em profundidade - mas possibilita a articulação em um nível mais específico.

Em "Eureka", o plano não é sinônimo do filme, mas sua matéria-prima. A repetição dos fotogramas afirma a presença de cada um deles como entidade fotográfica, composições congeladas no tempo, tornando evidentes suas propriedades gráficas. Mas a manutenção do movimento, especialmente o movimento com frequência e direção nitidamente determinadas, enfatiza também o caráter de representação de um evento. É essa tensão entre a superfície e a profundidade, entre a imagem fixa e a imagem fugidia, que é tratada por Gehr sobre a estrutura do plano.

Assim como em "Serene Velocity", não é permitida em "Eureka" a experiência direta do espaço - neste caso, sua travessia em "tempo real". O movimento do plano tem seu andamento reduzido, e o movimento da película, evidenciado pelas variações mínimas entre os fotogramas, parece por vezes ganhar a frente como se buscasse sua própria liberação, mostrando de uma só vez a imensa quantidade de etapas em um movimento e a riqueza de detalhes decorrente da multiplicação dessas etapas em um mesmo quadro. O palimpsesto de Gehr coordena duas dimensões históricas em uma composição que cristaliza formas e as evapora em seguida. O filme é um microscópico peculiar, que expande a percepção temporal tanto quanto a espacial, mas o mecanismo que permite a observação torna-se, ele mesmo, parte da observação, transfigurando o material num processo que é "em parte material, e em parte algo a mais" (MacDONALD, 1990, p. 16). Gehr propõe uma espécie de princípio de incerteza cinematográfica: uma vez que apreendemos a posição de um fotograma, seu momento é perdido, mas se apreendemos o momento de um fotograma, sua posição é perdida. 
Aparições, coisas que surgiam no mundo sem que existissem causas, coisas que estavam separadas do universo pois eram efeitos puros, sem nada que os antecedesse, sem uma lógica, sem uma lei: os jogadores atiravam os dados para a mesa e os resultados apareciam. Como fantasmas... - Gonçalo M. Tavares (2004, p. 27)
\end{abstract}

Consideremos duas analogias pelas quais o olhar crítico pode se referir a uma obra: o organismo e o mecanismo. Malcolm Turvey propõe os termos como extensões de dois "paradigmas científico-filosóficos" (2007, p. 6-9). O paradigma mecanicista seria representado pela análise redutiva, pela compreensão nos termos das partes constituintes e do isolamento das relações entre elas - relações sem propósito especial. O paradigma organicista, por sua vez, seria representado pela síntese holística, pela compreensão nos termos da totalidade do conjunto, da interdependência das relações - relações com direcionamento teleológico. Um organismo é normalmente mencionado como aquilo que exibe uma complexidade infinita, como se uma rede de causas além da compreensão humana estivesse por trás daqueles processos. O mecanismo, por outro lado, seria aquilo que tem sua complexidade reduzida a processos finitos, conscientemente dispostos, e reconhecíveis por análise empírica. É nesse sentido que encaramos um organismo como aquilo que possui "vida própria", enquanto o mecanismo apenas reproduz seu funcionamento externo, e não seu princípio vital interior.

Poderia uma máquina suficientemente complexa representar a infinidade orgânica? A diferença parece dar-se na aparência de determinação dos elementos. A percepção das causas por trás da ordem seria o obstáculo a ser superado. Para que a máquina não aparente determinação completa, ela deve talvez incluir, em sua própria organização, uma série de interferências, de elementos que tornem a ordem mais difusa, que criem discrepâncias ou curtos-circuitos no funcionamento do sistema, como se este pudesse interagir com o ambiente e nele estabelecer seu propósito específico.

Em todos os filmes citados, a aspiração mecânica é explícita. Cada um deles se atém a um local e um procedimento técnico, executando, dentro desse campo, variações que terminam por preencher toda a duração. "Morning" se concentra em um quarto, e nele a luz é variada. "Reverberation" utiliza um conjunto reduzido de planos, sobre os quais são manipulados o som e a granulação. "Serene Velocity" se passa em um único corredor, onde a distância focal é o elemento articulado. "Still" faz com que o mesmo enquadramento se multiplique através das sobreposições. "Eureka" parte de um travelling em uma rua para, sobre ele, executar modulações de movimento e luminosidade. Os filmes se voltam, portanto, a espaços, e encontram na própria estrutura de tais espaços a organização de sua forma composicional, uma arquitetura fechada. ${ }^{3}$

3 Além dos filmes comentados, poderíamos citar outros que desenvolvem as mesmas estratégias em diferentes contextos. Wait (1968) é um desdobramento de Morning, incluindo, desta vez, figuras humanas no centro do quadro. History (1970) baseia-se, como Reverberation, na granulação, mas se livra completamente de "imagens", e trata uma superfície em diferentes gradações de luz e sombra. Vale lembrar ainda que é considerado aqui apenas o "período fílmico" de Gehr. A partir de 2000, o vídeo digital predomina em sua obra. 
Se nos fosse possível estender os rolos de cada um dos filmes e observar sua totalidade, veríamos o rigor da construção, a manutenção de um "fundo" (os espaços), a divisão aritmética das partes, o aspecto combinatório das alterações - isto é, a estrutura construída por Gehr, seu artefato, decorrente de técnicas específicas sobre as quais exerceu controle. Esse controle é estrito no nível do enquadramento, geralmente centralizado ou reforçando a perspectiva. As linhas demarcam os limites da imagem, estabelecem as divisões, inauguram um regime gráfico. É estrito o controle também no nível da duração, chegando ao extremo da contagem de fotogramas em Serene Velocity. Na regularidade geral da organização, o sentido é o da pura relação: a declaração de um espaço-tempo particular do filme, autônomo, mecânico.

Entretanto, neste cenário sólido e determinado, a presença de uma única substância instável altera fortemente o propósito da composição. A câmera em "Morning" centraliza a janela em um enquadramento fixo, mas a luz invade o quarto, irradia sua energia em todas as direções, e tudo se dissolve no branco completo, fazendo com que mesmo o enquadramento seja desestabilizado. O corredor em "Serene Velocity" está vazio, mas o batimento entre as distâncias revela aos poucos os objetos dispostos em sua extensão, impondo sua forma e presença, surgindo e desaparecendo na trajetória fílmica. As pessoas em "Reverberation" são cobertas pela granulação; os veículos em "Still" são remodelados pelas sobreposições. Os resultados partem da abordagem consciente, mas é como se esta fosse uma armadilha para atrair tudo o que é complexo demais para ser planejado. Ao recusar o direcionamento causal criado pela narrativa, e ao concentrar a atenção em um número reduzido de procedimentos, Gehr faz da regularidade espaço-temporal uma grade através da qual somos capazes de perceber as mais sutis variações materiais. Sem tais variações, os filmes seriam entidades imutáveis. Mais do que uma simples aspiração à coexistência entre ordem e acaso, o que encontramos nessas obras parece ser uma investigação sobre os mínimos denominadores comuns que permitem a ordem e o acaso no cinema. De um lado, as propriedades físicas do movimento, as características mecânicas do fotograma e do plano, sua capacidade de ser medido ou quantificado. De outro, a maneira como a luz e a cor são percebidas, como definem a visão através de grãos e transparências, como determinados efeitos parecem brotar na cognição em momentos inesperados. Dentro do cristal, a chama brilha de maneira vacilante, imprevisível.

Tudo o que não é da ordem do controle consciente ganha assim o estatuto de uma lei natural, inevitável. Nesse cinema que rejeita a construção narrativa, as leis da "máquina do cinema", suas próprias partes, precisas e regulares, devem elas mesmas contribuir na criação de um drama das formas. Nessa dimensão baseada no rigor técnico e na recorrência de materiais, há algo que surge "sem que existam causas", algo separado do universo externo, "efeitos puros, sem nada que os antecedesse". Algo que existe entre a realidade material do mundo e a realidade material do cinema: 


\begin{abstract}
A câmera não cria as coisas, ela recebe sua luz da realidade; mas o projetor tem sua própria luz. Um campo da teoria fílmica, o campo que enfatiza o realismo fotográfico, subordina o projetor à imagem documental da câmera; o outro campo, o campo que enfatiza a fantasia e o imaginário, subordina a câmera à imagem ilusória do projetor. Mas a imagem fílmica é tanto da câmera como do projetor: o fantasma material (PEREZ, 1998, p. 34).
\end{abstract}

A ênfase no caráter material da construção fílmica coexiste com a descoberta de tudo aquilo que só ganha vida durante o encontro com a obra: os movimentos particulares, irregulares e instáveis da própria máquina cinematográfica. Uma vez estabelecidos os limites, as regras do jogo, uma vez jogados os dados, o cineasta se retira e observa as incalculáveis variáveis sendo cruzadas, desdobradas, amplificadas. O simples contato entre as partes, a mais delicada fricção entre as peças, fazem com que o universo fílmico pareça ter uma vida própria. O plano, a decupagem, a cena, o raccord, a continuidade, a opacidade: tudo deve ser construído; mas, no decorrer dessa construção, percebemos que os desvios apresentados - desvios que poderiam ser vistos como "erros" ou "ruídos" - levam a caminhos com equivalente expressividade. Os eventos são atomizados e fragmentados, mas sofrem depois uma fusão, em um novo ritmo, que os devolve ao fluxo do tempo pela projeção. Este processo não evoca o fantástico ou o sobrenatural; em vez da suspensão da descrença na realidade representada, existe a afirmação da presença das próprias técnicas e de seus resultados, de modo que "simplesmente aceitamos a presença de todo o filme como uma ilusão fílmica" (CORNWELL, 1977, p. 30).

O que encontramos nos filmes de Gehr é uma exploração da capacidade do cinema de atribuir vida a partes isoladas ou inanimadas - capacidade que se encontra mesmo em sua gênese como técnica de sugerir o movimento através de fotografias, mas que é expandida em várias direções por Gehr. É característico de seus filmes que se parta de objetos e espaços, que eventos naturais sejam decompostos, revistos, reinterpretados, e que ainda assim existam diversos tipos de movimento e transformação. Estes corpos e espaços transfigurados são algo como os fantasmas do cinema: fantasmas cujo passado ou memória independem de qualquer ficção ou mesmo dos eventos aos quais parecem relacionados, e cuja invocação depende inteiramente da eletricidade que atravessa os rolos de filme durante a projeção. Assim como não interfere diretamente nos eventos do mundo, Gehr também não interfere diretamente nas condições materiais da apresentação dos filmes: ele as conduz, como um regente, consciente de que existe algo que deve nascer do próprio núcleo da máquina fílmica. Uma vez compostos os filmes, eles são entregues ao projetor como a um intérprete. Disso resulta "um cinema em que a ação, o agente e o meio são inextricavelmente fundidos", e onde a captura de uma ideia pelo material fílmico "cumpre a promessa de um sereno distanciamento" (SITNEY, 2002, p. 203).

Não é, portanto, o mundo que encontramos nos filmes de Gehr, ou sua recriação baseada na percepção usual. É o mundo particular do cinema, descoberto em suas regras únicas e filtrado pela percepção de um criador: uma arte que "não reflete a vida, mas 
encarna a vida da mente" (GEHR, 1972). O homem que um dia encontrou no cinema o abrigo para uma tempestade se tornou uma espécie de cientista lírico, um investigador da câmera, da película e da sala de projeção, um especialista em uma ciência válida unicamente por alguns instantes, mas que nesse intervalo é capaz de trazer à vida toda espécie de formas apenas para em seguida fazê-las desaparecer na escuridão.

Lucas Baptista é doutorando em Meios e Processos Audiovisuais na ECA-USP.

lucasbaptista2205@gmail.com

\section{Referências}

CALVINO, I. Seis propostas para o próximo milênio. São Paulo: Companhia das Letras, 1990.

CORNWELL, R. "Works of Ernie Gehr from 1968 to 1972", Film Culture, n. 63-64, 1977.

FOREMAN, R. "On Ernie Gehr's Film 'Still', Film Culture, n. 63-64, 1977.

GEHR, E. "Program notes by Ernie Gehr", Film Culture, n. 53-55, 1972.

MacDONALD, S. A Critical Cinema 5: Interviews with Independent Filmmakers. Berkeley: University of California Press, 2006.

. "Camera Obscura/Lens/Filmstrip", Film Quarterly, Vol. 43, n. 4, verão de 1990.

PEREZ, G. The Material Ghost: Films and Their Medium. Baltimore: The Johns Hopkins University Press, 1998.

SITNEY, P. A. Eyes Upside Down: Visionary Filmmakers and the Heritage of Emerson. Oxford: Oxford University Press, 2008. 2002.

Visionary Film: The American Avant-Garde, 1943-2000. Nova York: Oxford University Press,

TAVARES, G. M. A Máquina de Joseph Walser. São Paulo: Companhia das Letras, 2004.

TURVEY, M. "Vertov: Between the Organism and the Machine", October, n. 121, verão de 2007.

Texto recebido em fevereiro

e aprovado em julho de 2016. 